\title{
A Neural Network Approach to Financial Forecasting
}

\author{
P. Enyindah \\ Department of Computer Sciences, \\ University of Port Harcourt, \\ Choba, Nigeria.
}

\author{
Onwuachu Uzochukwu C. \\ Department of Computer Sciences, \\ Imo state University, \\ Owerri, Nigeria.
}

\begin{abstract}
As the world economy keeps on changing, financial institutions and investors always look forward to a system by which they can monitor the dynamic financial state of the world. This calls for a system that could simulate and predict financial positions based on financial market trends in order to manage and identify the best package to invest in. The paper is aimed at developing a neural network application to predict interest rate on loan investment in Nigerian bank using the back propagation neural network.It forecastinterest rate on loan investment in three areas which include commerce, education, and rent/housing. The simulation was done using Matlab 2008. From the results obtained the Mean Squared Error values 3.99104e-6 in the Training, 3.597228e-5 in the validation and 9.9464314e-6 in the testing which shows that the prediction was done with minimum amount of error.
\end{abstract}

\section{Keywords}

Neural Network, back propagation, Mean Square Error, Training, Validation, and Prediction

\section{INTRODUCTION}

Faced with intense competition and rising demand for loans by Borrowers, most banks are exploring ways to use their data assets to gain a competitive advantage. The Business of lending is gradually becoming a major target for many banks; as a result there is high competition among the financial institutions. This has create need to raise the quality of giving loans and good preparation to increase the financial stability of the Banks. With the increasing economic globalization and improvements in information technology, large amounts of financial data are being generated and stored, and in the light of changing business environments, managers are seeing the need for more flexible predicting models.

Managing loan requires seeing through future trends in financial market. An artificial neural network is an adaptive system that changes its structure based on external or internal information that flows through the network during the learning phase to make time series prediction. Neural networks are non-linear statistical data modeling tools or information processing paradigm that have remarkable ability to derive meaning from complicated or imprecise data. The paper is aimed at developing a neural network application to predict loan investment in Nigerian bank using the back propagation neural network. It forecast loan investment in three areas which include commerce, education, and rent/housing.

\section{LITERATURE REVIEW}

Anyaeche and Ighravwe, ( 2013), worked on Predicting performance measures using linear regression and neural network: A comparison Their work uses artificial neural network, Back Propagation Artificial Neural Network (BP$\mathrm{ANN}$ ), as an alternative predictive tool to multi-linear regression, for establishing the interrelationships among productivity, price recovery and profitability as performance measures. A 2-20-20-1 back propagation artificial neural network was proposed. Productivity and price recovery served as independent variables while profitability was used as the dependent variable in the BPANN architecture. It was observed that BA-ANN model has Mean Square Error (MSE) of 0.02 while Multiple Linear Regression (MLR) has MSE of 0.036 . This study concluded that artificial neural network is a more efficient tool for modeling interrelationships among productivity, price recovery and profitability. [2]

Zahra and Seyedmohsen (2014), worked on comparing the capabilities of Neural Networks and Data Envelopment Analysis in predicting corporate profitability. Their study shows an appropriate algorithm for predicting the profitability to the decision makers [1]

Mumtaz et al (2011), worked on estimating financial failure of the Turkish Banks using Artificial Neural Network. In their study, financial ratios that are financially effective and indicate the performance of banks in Turkey are given. Based on these performance ratios, two models are developed for estimating the probable financial failure. One of them is the logistic regression and the other one is the artificial neural network model. The performance of the artificial neural network model is better than the logistic regression model for estimating the financial failures of the banks. [3]

Rimvydas et al, (2007), worked on a flexible Neural Network for ATM cash demand forecasting. Their paper presents an artificial neural network based approach in support of cash demand forecasting for automatic teller machine (ATM). The results have showed good forecasting ability of ANN. The recent stage their proposed system is in the implementing phase for cash management tasks in ATM network. [4]

Saad M. Darwish, (2013), worked on a methodology to Improve cash demand forecasting for ATM Network. His results from ATM cash forecasting shows the feasibility and effectiveness. [5]

Reza and Mehdi, (2013), worked on assessment of Customer Credit through Combined Clustering of Artificial Neural Networks, Genetics Algorithm and Bayesian, Probabilities. In their work customer credit was assed using the combination of Genetics Algorithm, Bayesian, Probabilities and Neural network. It was compared with the methods such as Clustering-Launched Classification (CLC), Support Vector Machine (SVM) as well as GA+SVM where the genetics algorithm has been used to improve them. [7]

Rimvydas et al,(2008), Cash Demand Forecasting For ATM Using Neural Networks And Support Vector Regression Algorithms, In their paper two different methods are used to forecast the daily cash demand for automatic teller machines (ATM). The first method is based on flexible artificial neural network (ANN). The generalization properties of this ANN were improved using special adaptive regularization term. The second forecasting method employs the support vector regression (SPR) algorithm. Performed simulation studies and 
experimental tests showed tolerable forecasting capacities using the both proposed methods. Despite the today's overenthusiastic beliefs about the capabilities of SPR, their investigation showed however that for this application slightly better result can be achieved using forecasting method based on flexible ANN. [6]

Qeethara et al, (2010), worked on Neural Networks in Bank Insolvency Prediction, they were predicting bank insolvency before using neural networks in order to avert bankrupt. From the result it is obvious from the results that SOM gives better results than feed-forward backpropagation network. [8]

Dagmar and Jiří, (2011), in their work financial forecasting using Neural Networks China-USA business review. From the result it was seen that artificial neural network is a tool for financial forecasting. [9]

\section{MATERIALS AND METHODS}

For effective training of data using the back propagation algorithm, we used data from the Imo State microfinance bank at Owerri, Imo State, Nigeria. The study was focused on the rate at which Customers have demanded for Loans. The data collected are data reflecting the bank's Loan transaction from the period of five years and two months (16/02/2009$17 / 04 / 2014)$.Our problem is to predict the yearly financial demand, so that the bank can make proactive and successful preparation. The input variables used are twelve, which include: The amount of loan granted, Interest rate per annum, Duration (date granted to the expiring date), principal paid, interest and Total balance. In this Analysis we shall consider the Architectural design of the propose system

\subsection{Architectural Design of the System}

The architecture of this model consists of six input variable, three intermediate variables and one output variable. It is a schematic diagram of a 6-3-1 topology. The six input variables are: $\mathbf{X} \mathbf{1}_{\mathbf{1}}, \mathbf{X 1 _ { 2 }}, \mathbf{X} \mathbf{1}_{\mathbf{3}}, \ldots \mathbf{X} \mathbf{1}_{\mathbf{6}}$. The combination of these six input variables is from the data collected which will be entered into the system by the user. The hidden layer of $\mathbf{X} \mathbf{2}_{1}$, $\mathbf{X} \mathbf{2}_{2}, \mathbf{X} \mathbf{2}_{3}$ are intermediate variables which interact by means of weight matrices with adjustable weights to produce the output. It uses the Activation function to manipulate the inputs from the input layer in other to make the optimal prediction. The output layer contains one output variable which is the optimal prediction. Figure1 shows the neural network architecture of the proposed system.

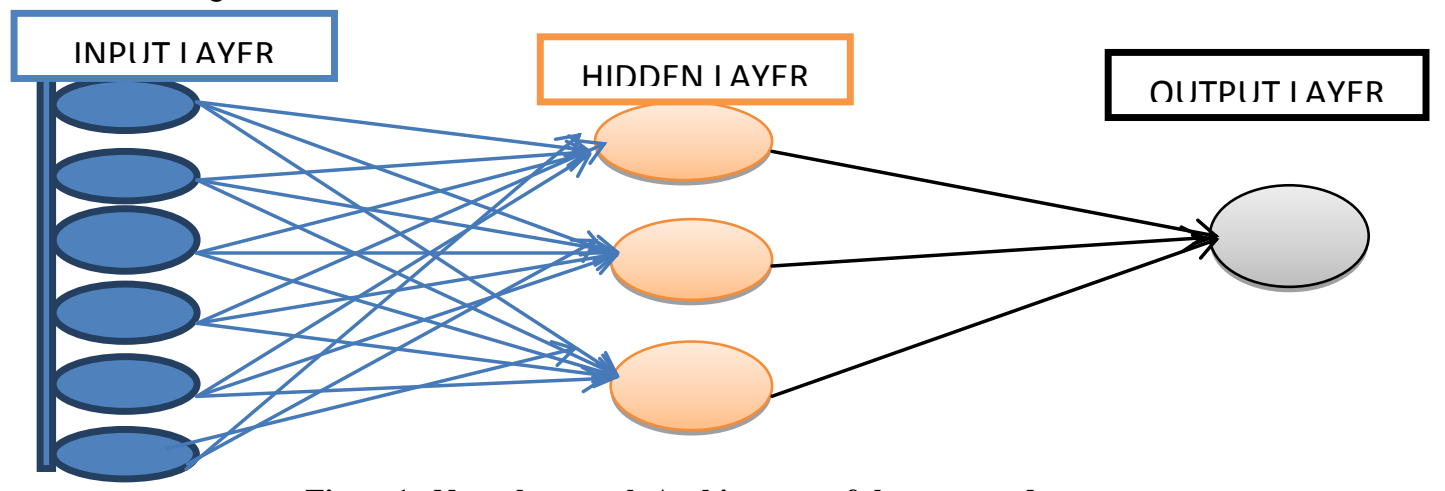

Figure1. Neural network Architecture of the proposed system

The input variables used include the following:

$\mathrm{A}_{i}$ the Amount Granted

$\mathrm{I}_{i}$ the interest rate

$\mathrm{L}_{i}$ Loan Duration

$\mathrm{P}_{i}$ The principal paid

$\mathrm{E}_{i}$ The Interest paid

$\mathrm{T}_{i}$ Total Balance

With all the input variables added together we have 6 input variables

\section{EXPERIMENTS AND RESULTS}

The simulation was done using Matlab. Figure 2.shows the Neural Network fitting tool for data selection. This Interface

helps in collection of input data and the target data from the work space.

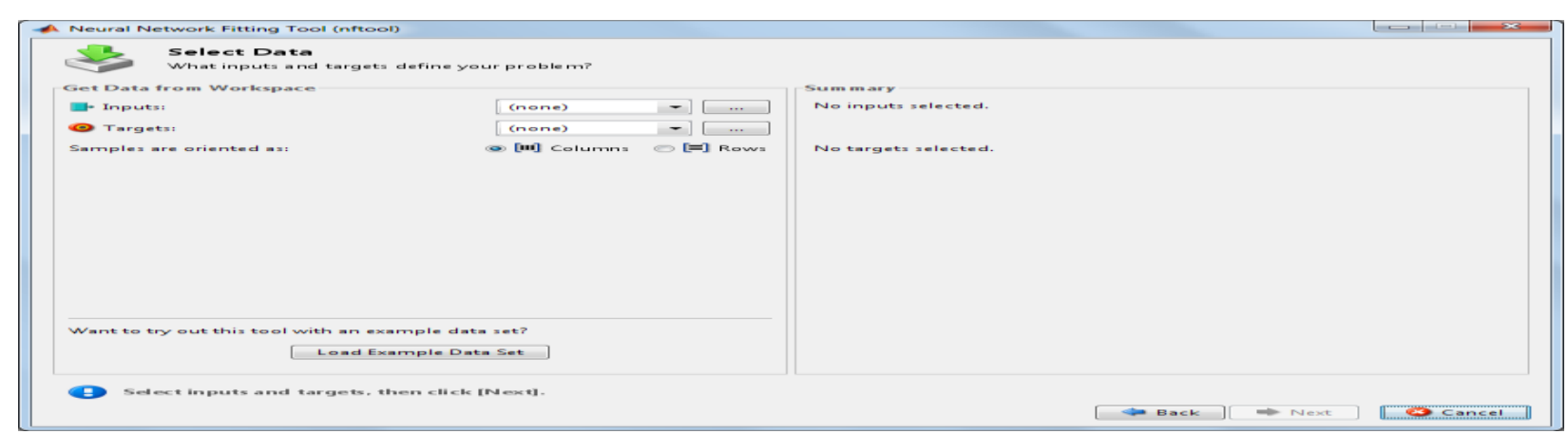

Figure 2. Neural Network Fitting Tool for Data Selection 
Figure 3 shows the Neural Network fitting tool for selection of network size. This interface gives the user the opportunity to select the number of neuron in the network's hidden layer.
The user can return to this panel and change the number of the neuron if the network does not perform well after training.

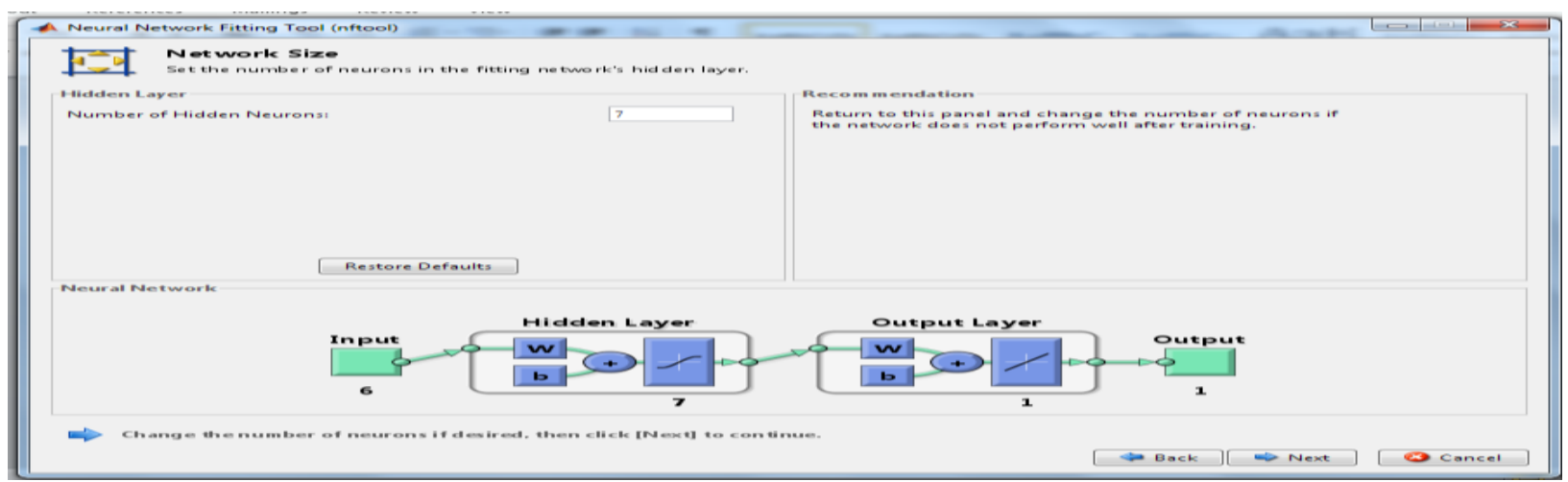

Figure 3 Neural Network Fitting Tool for Network Size Selection

Figure 4.shows the Neural Network training. The Neural Network model was trained using Levenberg-Marquardt back propagation. The network is trained to fit the inputs and the target. This means that neural network map between a data of numeric inputs and a set of numeric targets. Training automatically stops when generalization stops improving as indicated by the increase in the mean square error of the validation samples.

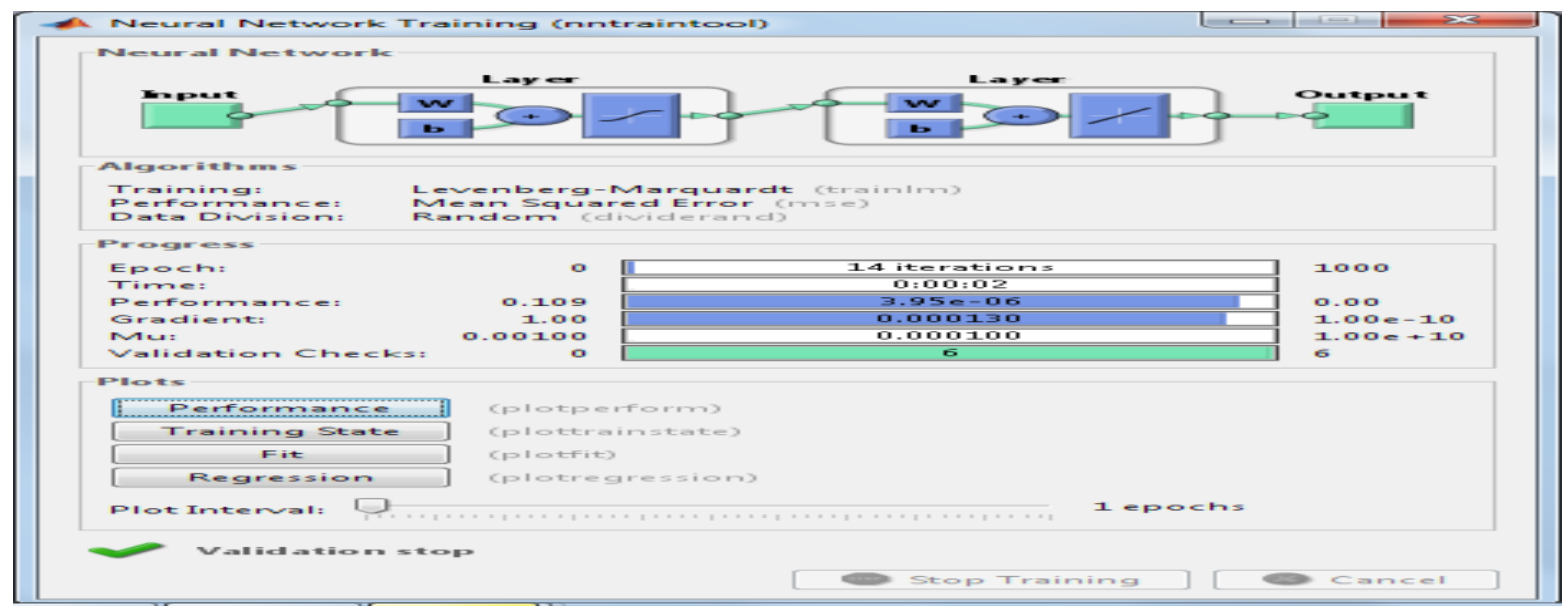

Figure 4. Neural Network Training Tool

The neural network fitting tool will help in training network and evaluation its performance using mean square error and regression analysis. Training multiple times will generate different results due to different initial condition and sampling. Figure 5.shows the result of the trained Network.

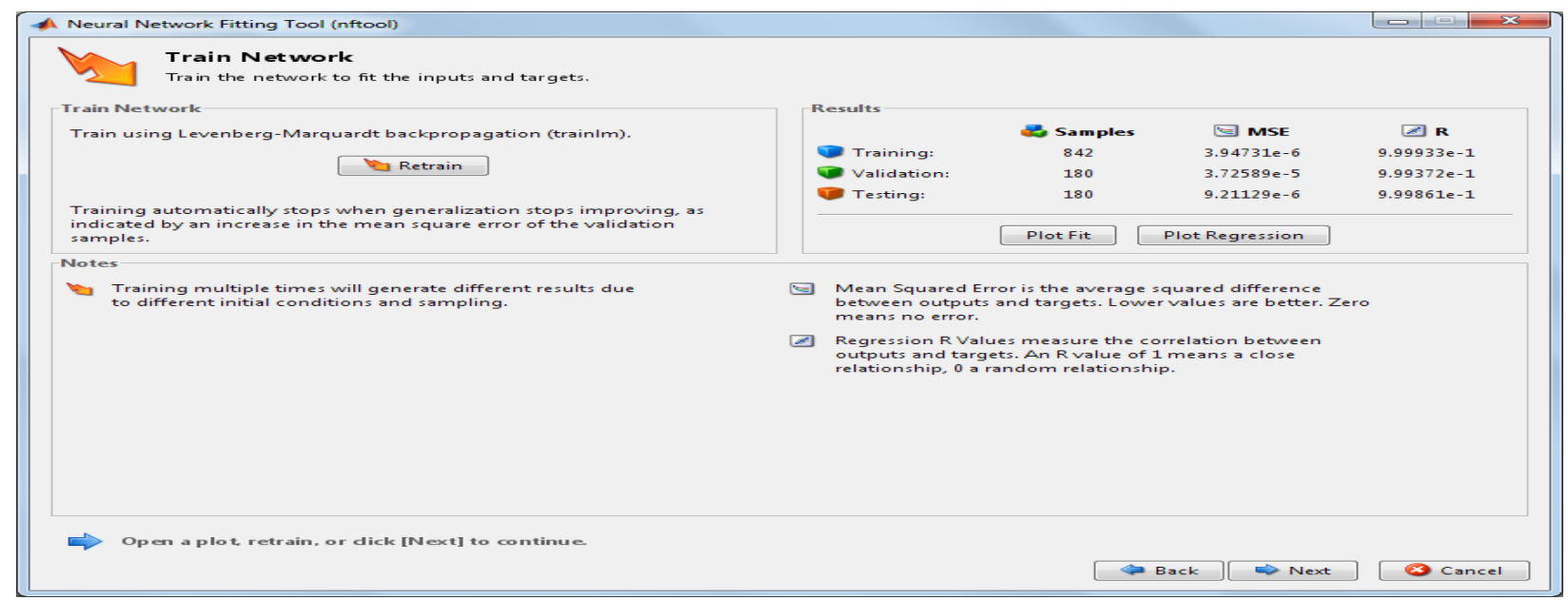

Figure 5.Neural Network Fitting Tool for Displaying the Result of the Trained Network. 


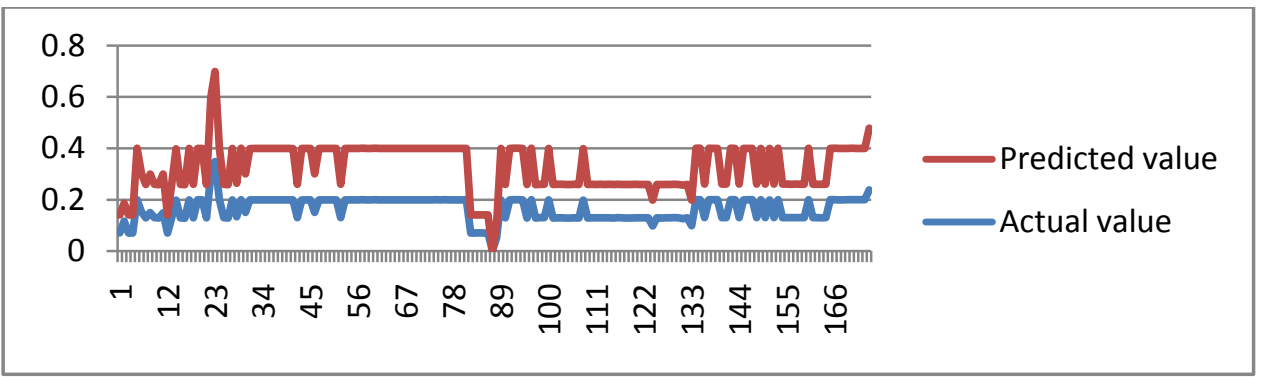

Figure 6: The graphical representation of the interest rate prediction on the loan given for Rent/Housing.

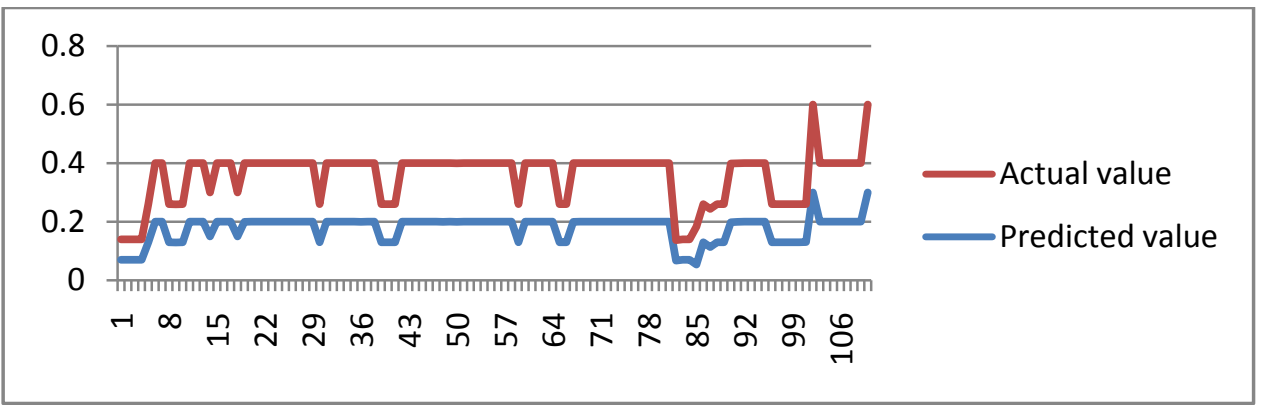

Figure 7: The graphical representation of the interest rate prediction on the loan given for Education.

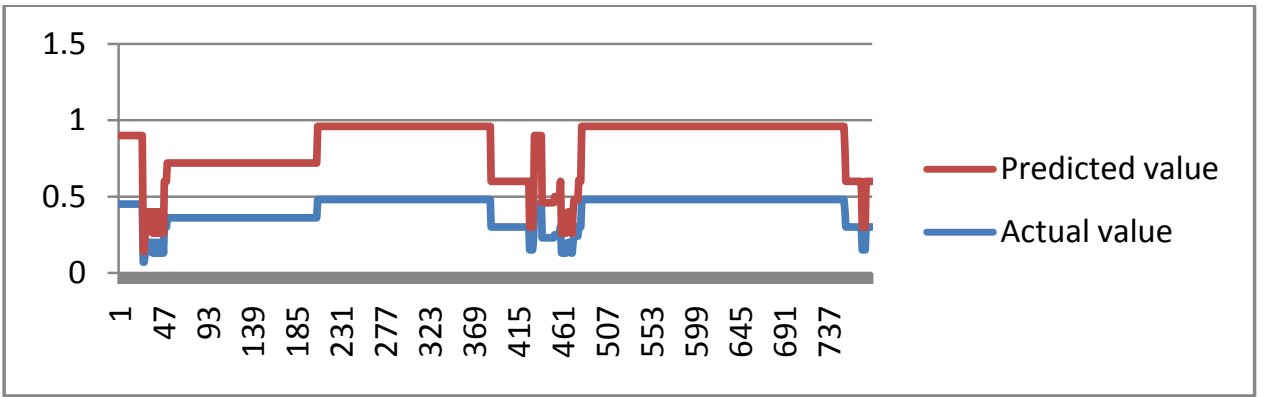

Figure 8: The graphical representation of the interest rate prediction on the loan given for Commerce.

\section{RESULT DISCUSSION}

Figure 6 shows the graphical representation of the interest rate prediction on the loan given for Rent/housing. From graph, it can be seen that the predicted value follows the actual target value show the prediction was done with the lowest minimum error.Figure 7 shows the graphical representation of the interest rate prediction on the loan given for Education. From graph, it can be seen that the predicted value follows the actual target value show the prediction was done with the lowest minimum error. Figure 8 shows the graphical representation of the interest rate prediction on the loan given for Commerce. From graph, it can be seen that the predicted value follows the actual target value show the prediction was done with the lowest minimum error.

\section{CONCLUSION}

This paper has shown that neural network can predict interest rate on loan investment in Nigerian bank. From the results obtained the Mean Squared Error values 3.99104e-6 in the Training, 3.597228e-5 in the validation and 9.9464314e-6 in the testing which shows that the prediction was done with minimum amount of error.

\section{REFERENCES}

[1] Zahra Poorzamania and SeyedmohsenRahanjamb, (2014), Comparing the Capabilities of Neural Networks and Data Envelopment Analysis in Predicting Corporate
Profitability, Technical Paper ISSN: 1607-7393 RRAMT 2014- Vol. 40, 1 - 111

[2] Anyaeche C. O. and Ighravwe D. E., (2013), Predicting performance measures using linear regression and neural network: A comparison, African Journal of Engineering Research Vol. 1(3), pp. 84-89,

[3] MumtazIpek, UfukBolukbas, and EminGundogar, (2011), Estimating Financial Failure of the TurkishBanks Using Artificial Neural Networks, the 2011 New Orleans International Academic Conference New Orleans, Louisiana USA 629

[4] RimvydasSimutis, Darius Dilijonas, LidijaBastina and JosifFriman, (2007), A Flexible Neural Network For Atm Cash Demand Forecasting, 6th WSEAS Int. Conference on Computational Intelligence, ManMachine Systems and Cybernetics, Tenerife, Spain, December 14-16, 162

[5] Saad M. Darwish, (2013), A Methodology to Improve Cash Demand Forecasting for ATM Network, International Journal of Computer and Electrical Engineering, Vol. 5, No. 4,

[6] [6] Reza Mortezapour and Mehdi Afzali, (2013), Assessment of Customer Credit through Combined Clustering of Artificial Neural Networks, Genetics Algorithm and Bayesian, Probabilities, (IJCSIS) 
International Journal of Computer Science and Information Security, Vol. 11, No. 12, 2013

[7] RimvydasSimutis, Darius Dilijonas, LidijaBastina,(2008), Cash Demand Forecasting For Atm Using Neural Networks And Support Vector Regression Algorithms, 20th EURO Mini Conference "Continuous Optimization and Knowledge-Based Technologies" (EurOPT-2008), Neringa, LITHUANIA , ISBN 9789955-28-283-9,
[8] QeetharaKadhim Al-Shayea, Ghaleb A. El-Refae, and ShurouqFathi El-Itter, (2010), Neural Networks in Bank Insolvency Prediction, IJCSNS International Journal of Computer Science and Network Security, VOL.10 No.5, $240-245$.

[9] Dagmar Blatná and JiříTrešl, (2011), Financial Forecasting Using Neural Networks China-USA Business Review, David Publishing ISSN 1537-1514, Vol. 10, No. 3, 169-175 